\title{
Prevention of $\gamma$-Radiation-Induced DNA Damage in Human Lymphocytes Using a Serine-Magnesium Sulfate Mixture
}

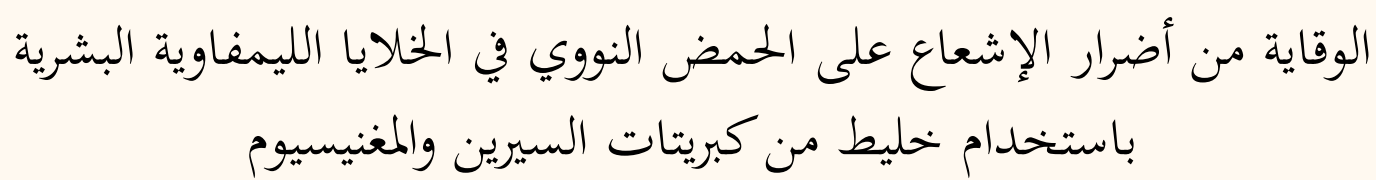

وحيد تشانجيزي، مونا بهرامي، مهبد اصفهاني، وحيد شتاب بوشهري

ABSTRACT: Objectives: Ionising radiation has deleterious effects on human cells. N-acetylcysteine (NAC) and cysteine, the active metabolite of NAC, are well-known radioprotective agents. Recently, a serine-magnesium sulfate combination was proposed as an antidote for organophosphate toxicity. This study aimed to investigate the use of a serine-magnesium sulfate mixture in the prevention of $\gamma$-radiation-induced DNA damage in human lymphocytes as compared to NAC and cysteine. Methods: This study was carried out at the Iran University of Medical Sciences, Tehran, Iran, between April and September 2016. Citrated blood samples of $7 \mathrm{~mL}$ each were taken from 22 healthy subjects. Each sample was divided into $1 \mathrm{~mL}$ aliquots, with the first aliquot acting as the control while the second was exposed to 2 Gy of $\gamma$-radiation at a dose rate of $102.7 \mathrm{cGy} /$ minute. The remaining aliquots were separately incubated with $600 \mu \mathrm{M}$ concentrations each of serine, magnesium sulfate, serine-magnesium sulfate, NAC and cysteine before being exposed to $2 \mathrm{~Gy}$ of $\gamma$-radiation. Lymphocytes were isolated using a separation medium and methyl-thiazole-tetrazolium and comet assays were used to evaluate cell viability and DNA damage, respectively. Results: The serine-magnesium sulfate mixture significantly increased lymphocyte viability and reduced DNA damage in comparison to serine, magnesium sulfate, NAC or cysteine alone $(P<0.01$ each). Conclusion: The findings of the present study support the use of a serine-magnesium sulfate mixture as a new, non-toxic, potent and efficient radioprotective agent.

Keywords: Ionizing Radiation; Gamma Rays; DNA Damage; Radioprotective Agents; Serine; Magnesium Sulfate; N-Acetylcysteine; Cysteine.

الملخص: الهدف: الإشعاعات المؤينة مثل الأشعة جاما والأشعة السينية لها العديد من الآثار الضارة على الخلايا البثرية. من المعروف

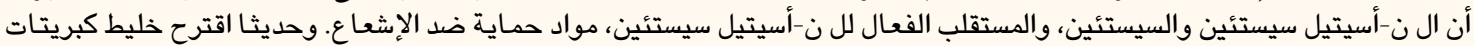

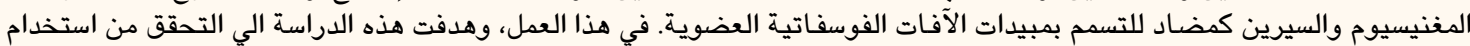

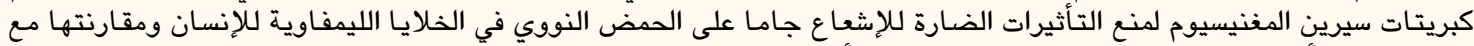

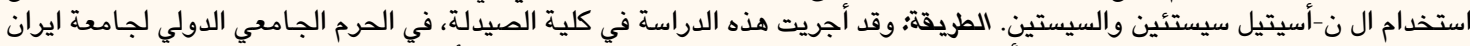

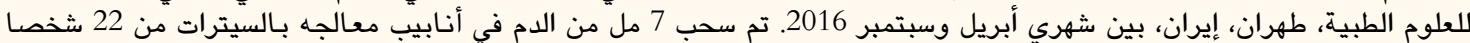

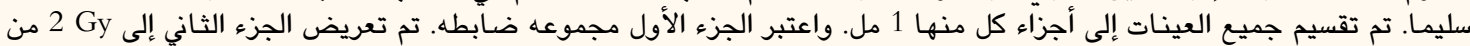

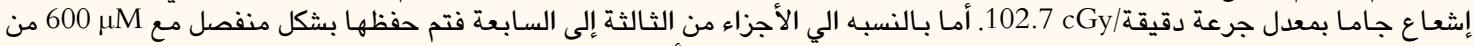

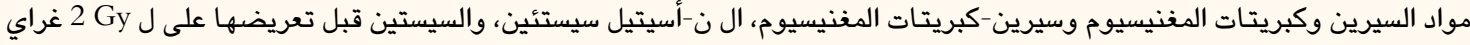

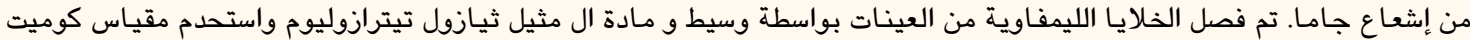

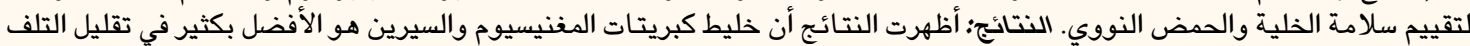

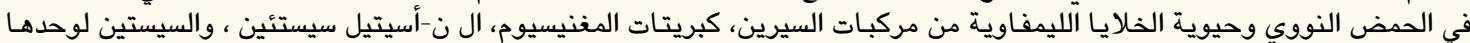
(0.01> P، كل واحد) الخلاصة: تدعم نتائج هذا البحث أستخدام خليط كبريتات المغنيسيوم والسيرين كعامل جديد قوي، وفعال في الإل في الحماية

ضد خطر الإشعاع.

الكلمات المفتاحية: الإشعاعات المؤينة؛ أشعة جامـا؛ تلف الحمض الذووي؛ مواد حماية ضد الإشعاع؛ السيرين؛ كبريتات المغنيسيوم؛ ن -أسيتيل سيستين؛ السيستين.

\section{AdvanCes in KNOWledge}

The findings of the present study demonstrated that a serine-magnesium sulfate mixture reduced $\gamma$-radiation cytotoxicity and genotoxicity in isolated human lymphocytes.

Moreover, the radioprotective effects of a serine-magnesium sulfate mixture were greater than that of $N$-acetylcysteine and its active metabolite, cysteine. As such, these findings indicate that a mixture of serine and magnesium sulfate mixture may be a new and nontoxic radioprotective agent. 


\section{Application to Patient Care}

The results of this study may potentially be utilised at emergency medicine, radiotherapy and radiology centres to prevent and/or reduce y-radiation toxicity among personnel; however, extensive in vivo studies are needed to confirm the safety and efficacy of this new radioprotective agent among both animals and humans.

B OTH $\gamma$ - AND X-RAYS ARE FORMS OF IONISING radiation with sufficient energy to displace electrons from molecules; these released electrons can subsequently have deleterious effects on human cells, particularly highly proliferating cells, with one of the most important cellular effects being DNA damage. ${ }^{1-3}$ Lymphocytes are among the most radiosensitive cells which can be used to evaluate the effect of ionising radiation on humans. ${ }^{1-3}$

A simple, sensitive, versatile, rapid and economical method of assessing DNA damage is comet assay or single-cell gel electrophoresis; this involves embedding cells in a low-melting-point agarose (LMPA), lysis of the cells in neutral or alkaline conditions $(\mathrm{pH}>13)$ and electrophoresis of the suspended lysed cells. ${ }^{4-6} \mathrm{~A}$ methyl-thiazole-tetrazolium (MTT) assay is a colourimetric assay for assessing cell viability and metabolic activity in which a yellow water-soluble tetrazolium dye is reduced by mitochondrial nicotinamide adenine dinucleotide phosphatedependent oxidoreductase enzymes of live, but not dead, cells to a purple formazan product that is insoluble in aqueous solutions. Under defined conditions, a MTT assay therefore reflects the number of viable cells present. ${ }^{7,8}$

Serine is an analogue of cysteine, a well-known radioprotective agent. ${ }^{9-11}$ A serine-magnesium sulfate combination was recently proposed as an antidote for organophosphate pesticide poisoning by an ionradical mechanism. ${ }^{12}$ This study therefore aimed to investigate the prevention of $\gamma$-radiation-induced DNA damage in human lymphocytes using a serinemagnesium sulfate mixture in comparison to $\mathrm{N}$-acetylcysteine (NAC) and cysteine. Comet and MTT assays were used to evaluate DNA damage and cell viability, respectively, in isolated lymphocytes.

\section{Methods}

This study was carried out at the School of Pharmacy of the Iran University of Medical Sciences, Tehran, Iran, between April and September 2016. A total of 22 healthy human subjects were recruited to participate. The sample size was determined according to the following formula for continuous variables: ${ }^{13}$

$$
\mathrm{N}=1+2 C\left(\frac{s}{d}\right)^{2}
$$

where the constant $\mathrm{C}$ is dependent on the values of $\alpha$ (false-positive) and $\beta$ (false-negative). For $\alpha=0.05$ and $1-\beta=0.9, C$ is $10.51, s$ is the standard deviation of a variable and $d$ is the magnitude of the difference. Accordingly, for $d=s$, the sample size was calculated as 22. Each recruited participant was subsequently asked to fill out a questionnaire design to elicit information on their health status, use of medications, occupational history and exposure to pesticides. Individuals with a history of diabetes mellitus, hypertension, liver disease, anaemia, malnutrition, cancer or other chronic illnesses, cigarette smoking, alcohol or drug use and a history of radiotherapy were excluded.

The following chemicals and solutions were purchased: L-serine, NAC, L-cysteine, potassium dihydrogen phosphate, disodium hydrogen phosphate, sodium chloride, potassium chloride, sodium hydroxide, trisodium citrate dihydrate, absolute ethanol, tris(hydroxymethyl)aminomethane hydrochloride (tris- $\mathrm{HCl}$ ), ethylenediaminetetraacetic acid (EDTA) and its disodium salt dihydrate ( $\left.\mathrm{Na}_{2} \mathrm{EDTA}\right)$, trypan blue, 4-(2-hydroxyethyl)-1-piperazineethanesulfonic acid (HEPES), dimethyl sulfoxide (DMSO), glycine and MTT (Merck KGaA, Darmstadt, Germany); normal melting agarose (NMA), LMPA, fetal bovine serum (FBS) and SYBR Green (Sigma-Aldrich Co. Ltd., Dorset, UK); and Lymphosep ${ }^{\circledR}$ (Biowest, Nuaillé, France). Stock solutions of NAC, L-cysteine, L-serine, magnesium sulfate and an L-serine-magnesium sulfate mixture were stored in the dark at $4{ }^{\circ} \mathrm{C}$. Each solution was then separately prepared in $0.9 \%$ of weight/volume $(\mathrm{w} / \mathrm{v})$ sodium chloride in distilled water (i.e. normal saline) to produce $60 \mathrm{mM}$ concentrations.

A 7-mL blood sample was obtained from each participant by venipuncture and immediately citrated with trisodium citrate at a concentration of $3.8 \% \mathrm{w} / \mathrm{v}$ in a ratio of 1:9 parts of blood to prevent clot formation. ${ }^{14}$ All samples were divided into $1 \mathrm{~mL}$ aliquots. The first aliquot was considered the control. The second aliquot was exposed to 2 Gy of $\gamma$-radiation at a dose rate of $102.7 \mathrm{cGy} /$ minute using a Theratron ${ }^{\circledR} 780$ Cobalt-60 Therapy Unit (Theratronics Ltd., Ottawa, Canada). The remaining aliquots were pre-incubated for 60 minutes with $10 \mu \mathrm{L}$ each of the NAC, L-cysteine, L-serine, magnesium sulfate and L-serine-magnesium sulfate mixture solutions at a final concentration of $600 \mu \mathrm{M}$ 
each in a $37{ }^{\circ} \mathrm{C}$ water bath before being exposed to 2 Gy of $\gamma$-irradiation at a dose rate of 102.7 cGy/minute. Lymphocytes were isolated from the blood samples using the Lymphosep ${ }^{\circledR}$ (Biowest) separation medium according to the manufacturer's instructions. The samples were diluted at a ratio of 1:1 with a phosphatebuffered saline (PBS) solution and then carefully layered on the separation medium in a 1:1.5 ratio. Lymphocytes were separated by centrifugation at $400 \mathrm{x}$ g for 20 minutes at room temperature. Buffy coats containing lymphocytes were removed and washed twice more with a PBS solution and then centrifuged at $200 \mathrm{x}$ g for 10 minutes. Cell count and viability were determined using the trypan blue exclusion method. ${ }^{15}$ The lymphocytes were then diluted to 1,000 cells $/ \mu \mathrm{L}$ with a PBS solution containing $10 \mathrm{mM}$ of HEPES at a $\mathrm{pH}$ of 7.4.

Isolated lymphocytes were analysed using MTT and comet assays for cell viability and DNA damage, respectively. For the MTT assay, isolated lymphocytes were incubated for four hours at $37{ }^{\circ} \mathrm{C}$ with $5 \%$ carbon dioxide $\left(\mathrm{CO}_{2}\right)$ and humidified. ${ }^{16} \mathrm{~A}$ total of $50 \mu \mathrm{L}$ of MTT in a PBS solution at a concentration of $3 \mathrm{mg} / \mathrm{mL}$ was added to $200 \mu \mathrm{L}$ of suspended lymphocytes. The samples were wrapped in aluminium foil and incubated for four hours at $37{ }^{\circ} \mathrm{C}$. The PBS solution and MTT was removed by centrifugation at $300 \mathrm{x} \mathrm{g}$ for 10 minutes. A total of $200 \mu \mathrm{L}$ of DMSO and $25 \mu \mathrm{L}$ of a glycine buffer at a $\mathrm{pH}$ of 10.5 was added to each sample and mixed. The lymphocytes of each sample were then transferred to a 48-well plate and the corresponding absorbances were measured with a multi-mode microplate reader (Synergy $^{\mathrm{TM}}$ HT, Bio-Tek Instruments Inc., Highland Park, Illinois, USA) at $570 \mathrm{~nm}$.

For the comet assay, lymphocytes were first centrifuged at $300 \mathrm{x}$ g for 10 minutes and suspended in a Roswell Park Memorial Institute (RPMI) 1640 culture medium containing $10 \%$ FBS. They were cultured and incubated for 24 hours at $37{ }^{\circ} \mathrm{C}$ with $5 \% \mathrm{CO}_{2}$ and humidified. Cells were then collected in microtubes, centrifuged at $300 \mathrm{xg}$ for 10 minutes at $4{ }^{\circ} \mathrm{C}$ and then resuspended in the RPMI 1640 medium and diluted to 100 cells $/ \mu \mathrm{L}$. The comet assay was performed in alkaline conditions as previously described by Singh et al..$^{17}$ A total of $10 \mu \mathrm{L}$ of lymphocytes were mixed with $100 \mu \mathrm{L}$ of $0.5 \% \mathrm{LMPA}$ at $37{ }^{\circ} \mathrm{C}$. Then, $75 \mu \mathrm{L}$ of the mixture was placed on a precleaned microscope slide which had been covered with a thin layer of $0.5 \%$ NMA and allowed to solidify to promote even and firm attachment of the second layer. The suspension was spread on the surface with a coverslip. The slides were then refrigerated at $4{ }^{\circ} \mathrm{C}$ for five minutes to allow solidification of the agarose.
Without coverslips, the slides were subsequently immersed in a freshly prepared cold lysing solution consisting of $2.5 \mathrm{M}$ of sodium chloride, $100 \mathrm{mM}$ of $\mathrm{Na}_{2}$ EDTA, $10 \mathrm{mM}$ of tris- $\mathrm{HCl}$ at a $\mathrm{pH}$ of 10.0 and $1 \%$ Triton $^{\text {TM }}$ X-100 (Sigma-Aldrich Co. Ltd.). The solution was refrigerated for one hour to lyse the cells and permit DNA unfolding. Slides were then immersed in an alkaline buffer of $300 \mathrm{mM}$ of sodium hydroxide and $1 \mathrm{mM}$ of $\mathrm{Na}_{2} \mathrm{EDTA}$ at a $\mathrm{pH}$ of 13.0 for 20 minutes to allow unwinding of the DNA. Electrophoresis was conducted for 20 minutes at a voltage of $25 \mathrm{~V}$. Slides were then drained and immersed in a neutralisation buffer of $0.4 \mathrm{M}$ of tris- $\mathrm{HCl}$ at a $\mathrm{pH}$ of 7.5 for five minutes. They were dried and stained with $50 \mu \mathrm{L}$ of diluted SYBR Green (Sigma-Aldrich Co. Ltd.) at a ratio of 1:10 with a buffer of $1 \mathrm{mM}$ of EDTA and $10 \mathrm{mM}$ tris- $\mathrm{HCl}$ at a $\mathrm{pH}$ of 7.5 on each circle of dried agarose. The slides were again refrigerated for five minutes, gently tapped to remove the excess SYBR Green (Sigma-Aldrich Co. Ltd.) and allowed to dry completely at room temperature in the dark. They were then viewed under a fluorescence microscope (DP72 Digital Color Camera, Olympus, Tokyo, Japan) equipped with an ultravioletWG filter cube with an excitation filter of $510-560 \mathrm{~nm}$ and a barrier filter of $590 \mathrm{~nm}$. A total of 200 individual cells were screened for each aliquot. Undamaged cells were defined as cells with an intact nucleus without a tail while cells were considered damaged if they had visible tails (i.e. cells with a 'comet'-like appearance).

All statistical analyses were performed using the Statistical Package for the Social Sciences (SPSS), Version 23 (IBM Corp., Armonk, New York, USA). The cell viability of each sample was divided by that of the control sample and presented as a percentage of cell viability. A one-sample t-test was used to analyse differences in cell viability between samples that received only $\gamma$-radiation and the control group (deemed to have 100\% viability). Differences in cell viability between experimental groups were analysed using a one-way analysis of variance (ANOVA) test followed by Scheffe post hoc analysis. The DNA damage for each cell was quantified by calculating the tail moment (i.e. the product of tail length and fraction of total DNA in the tail) using OpenComet software, Version 1.3. ${ }^{18}$ Differences between the tail moments of experimental groups were also analysed using a one-way ANOVA test followed by Scheffe post hoc analysis. Charts comparing the differences between the experimental groups were rendered using SigmaPlot software, Version 12.0 (Systat Software Inc., San Jose, California, USA). Levene's test was used to determine the homogeneity of variance of tail moments and cell viabilities. A $P$ value of $<0.05$ was considered statistically significant. 


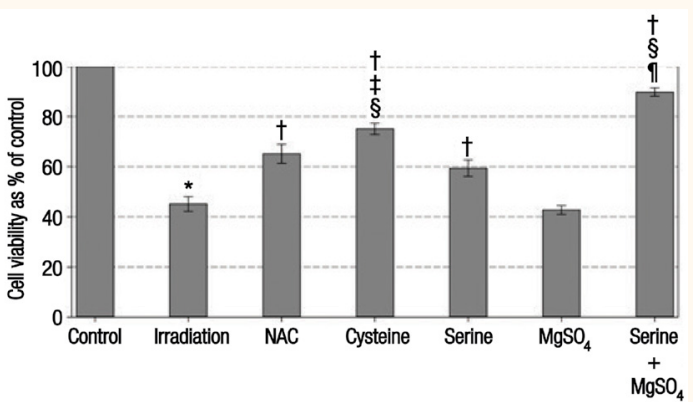

Figure 1: Chart showing mean lymphocyte viability in different experimental groups as a measure of radioprotection against $\gamma$-irradiation in human lymphocytes $(\mathrm{N}=22)$.

$\mathrm{NAC}=\mathrm{N}$-acetylcysteine $; \mathrm{MgSO}_{4}=$ magnesium sulfate .

"Statistically significant difference in comparison to the control group $(P<0.01)$. Statistically significant difference in comparison to the $\gamma$-irradiation group $(P<0.01){ }^{7}$ Statistically significant difference in comparison to the serine group $(P<0.01)$. Statistically significant difference in comparison to the NAC group $(P<0.01)$. Statistically significant difference in comparison to the cysteine group.

All procedures performed during this study were in accordance with the ethical guidelines of the Declaration of Helsinki. All of the subjects provided informed written consent prior to their inclusion in the study.

\section{Results}

All variances for cell viabilities were homogeneous $(P>0.05)$. The $\gamma$-irradiation significantly reduced lymphocyte viability in comparison to the control group $(45.1 \% \pm 3.0 \%$ of the control group; $P<0.01)$. In contrast, NAC significantly increased lymphocyte viability over that of the $\gamma$-irradiated group $(65.1 \%$ $\pm 3.7 \%$ of the control group; $P<0.01$ ). Cysteine significantly increased lymphocyte viability over that of the $\gamma$-irradiated, serine and NAC groups $(75.1 \% \pm 2.2 \%$ of the control group; $P<0.01$ each). Serine significantly increased lymphocyte viability over that of the $\gamma$-irradiated group $(59.4 \% \pm 3.2 \%$ of the control group; $P<0.01$ ); however, there was no statistical difference in cell viability between the NAC and serine groups $(P>0.05)$. Magnesium sulfate did not significantly increase lymphocyte viability in comparison to the $\gamma$-irradiated group $(42.7 \% \pm 1.7 \%$ of the control group; $P>0.05$ ). The serine-magnesium sulfate mixture significantly increased lymphocyte viability in comparison to the $\gamma$-irradiated, NAC, cysteine and serine groups $(89.7 \% \pm 1.6 \%$ of the control group; $P<0.01$ each) [Figure 1].

All variances for tail moments were homogeneous $(P>0.05)$. The mean tail moment of the control group was $4.7 \pm 0.4$. The $\gamma$-irradiation significantly increased tail moments in comparison to the control group $(34.1 \pm 2.2 ; P<0.01)$. Both NAC

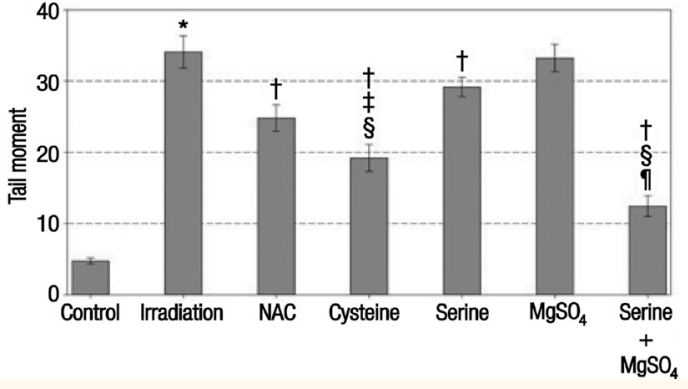

Figure 2: Chart showing mean tail moment in arbitrary units in different experimental groups as a measure of radioprotection against $\gamma$-irradiation in human lymphocytes $(\mathrm{N}=22)$.

$N A C=N$-acetylcysteine $; \mathrm{MgSO}_{4}=$ magnesium sulfate .

*Statistically significant difference in comparison to the control group $(P<0.01)$. 'Statistically significant difference in comparison to the $\gamma$-irradiation group $(P<0.05))^{7}$ Statistically significant difference in comparison to the serine group $(P<0.01)$. ${ }^{S}$ Statistically significant difference in comparison to the NAC group $(P<0.01)$. Statistically significant difference in comparison to the cysteine group.

and cysteine significantly reduced tail moments compared to the $\gamma$-irradiated group $(24.8 \pm 1.8$ and $19.2 \pm 1.9$, respectively; $P<0.01$ each); however, cysteine also significantly reduced tail moments in comparison to the NAC group $(P<0.05)$. Serine significantly reduced tail moments below those of the $\gamma$-irradiated group $(29.1 \pm 1.3 ; P<0.05)$, although cysteine was significantly stronger than serine in reducing tail moments $(P<0.01)$. There was no statistical difference between NAC and serine in terms of tail moment reduction $(P>0.05)$. Magnesium sulfate did not significantly reduce tail moments in comparison to the $\gamma$-irradiated group $(33.2 \pm 1.9$; $P>0.05)$. The serine-magnesium sulfate mixture significantly reduced tail moments in comparison to the $\gamma$-irradiated, NAC, cysteine and serine groups $(12.4 \pm 1.4 ; P<0.01)$ [Figure 2]

\section{Discussion}

The deleterious effects of ionising radiation on peripheral lymphocytes-such as DNA fragmentation-are commonly observed at least 24 hours after exposure to radiation. ${ }^{19}$ Moreover, nucleotide pool levels are generally lower in lymphocytes than other cell types, which may account for the observed increased sensitivity of lymphocytes to radiation. ${ }^{20}$ Low nucleotide pool levels hinder DNA double-strand rejoining, leading to more detectable strand breaks than other cell types. ${ }^{20}$ Peripheral human lymphocytes are quiescent cells, meaning that they are in the $G_{0}$ phase; thus, there is no need to rule out cell cycle arrest. $^{21,22}$ Since lymphocytes do not undergo normal mitosis, different phases of the cell cycle (i.e. $G_{1}, S, M$ and $G_{2}$ ) were not defined in the current study. ${ }^{21,22}$ 
The median lethal oral doses of cysteine, NAC and serine in rats are $1,890 \mathrm{mg} / \mathrm{kg}, 5,050 \mathrm{mg} / \mathrm{kg}$ and $14,000 \mathrm{mg} / \mathrm{kg}$, respectively; thus, these substances are classified as moderately toxic, slightly toxic and practically non-toxic, respectively. ${ }^{23-26}$ Currently, the mucolytic agent NAC is used for the treatment of acetaminophen overdoses, hepatotoxic mushroom poisoning and as an adjuvant antidote for organophosphate pesticide poisoning. ${ }^{27-29}$ Other medical uses for NAC include the treatment of radiocontrastinduced nephropathy, cyclophosphamide-induced haemorrhagic cystitis and a number of psychiatric disorders; it also has significant antiviral activity against influenza type A viruses. ${ }^{30}$ Moreover, NAC has been shown to replenish glutathione stores in cells and has free radical scavenging properties. ${ }^{30}$ It is a prodrug which is enzymatically metabolised (i.e. deacetylated) to its active metabolite cysteine by the liver and serves as a cysteine donor. The thiol group is reactive toward xenobiotics and seems to be responsible for the beneficial effects of cysteine in poisoning cases..$^{11,30}$

Both NAC and cysteine are known radioprotective agents whose radioprotective properties are attributable to the antioxidant and free radical scavenging characteristics of the thiol group. ${ }^{10,11}$ The pKa values - the values at which half of the functional group are ionised-of the thiol group have been shown to play an important role in the radioprotective properties of these agents, in that the more the thiol is ionised, the greater the radioprotection. ${ }^{31}$ Although comparable in reactivity to thiol for the scavenging of hydroxyl radicals, the thiolate ion (the ionised form of thiol) is more reactive in the repair of DNA. ${ }^{31}$ The pKa values of NAC and cysteine are 9.5 and 8.3, respectively. ${ }^{10,32}$ According to the Henderson-Hasselbalch equation, the NAC and cysteine thiol groups are $0.8 \%$ and $11.2 \%$ ionised, respectively, at a $\mathrm{pH}$ of 7.4 , which is the physiological $\mathrm{pH}$ of the human body. ${ }^{9}$ Serine is an analogue of cysteine which differs in that the sulphur atom in cysteine is replaced by an oxygen atom in serine hydroxyl; the pKa of the serine hydroxyl group is approximately 13.0 and is only $0.00025 \%$ ionised at a $\mathrm{pH}$ of $7.4{ }^{9}$ Magnesium sulfate has been shown to reduce the $\mathrm{pKa}$ value of high-pKa groups of oxygen nucleophiles, such as the serine hydroxyl group. ${ }^{9}$

In the present study, the radioprotective effect of an equimolar therapeutic concentration of a serine-magnesium sulfate mixture on $\gamma$-radiationinduced DNA damage was compared with NAC, cysteine, serine and magnesium sulfate alone. The concentrations of NAC, cysteine and magnesium sulfate were selected on the basis of their therapeutic plasma concentrations in humans. ${ }^{27,33,34}$ The results indicated that the serine and magnesium sulfate mixture had a greater radioprotective effect than NAC and cysteine alone. This may be related to the pKa reduction of the serine hydroxyl group by magnesium sulfate and the production of a more ionised hydroxyl group. An oxygen ion has a smaller ionic radius than sulphur and is therefore smaller in size; thus, the density of a negative charge is greater on the smaller-sized oxygen ion in comparison to the larger-sized sulphur ion. ${ }^{35}$ This may result in greater reactivity of the hydroxyl group compared to the thiol group.

The results of the current study also demonstrated that cysteine provided greater protection against $\gamma$-radiation-induced DNA damage and cell death in isolated human lymphocytes in comparison to NAC. This may be due to the fact that NAC needs to be metabolised by the liver, a process which was not conducted in the present in vitro study. The findings also showed that serine alone protected the lymphocytes against $\gamma$-radiation-induced DNA damage and cell death, although to a lesser degree than NAC or cysteine. This may be related to the presence of a small amount of the intracellular magnesium ion which partially reduces the pKa of the serine hydroxyl group, thereby resulting in a more ionised form of the hydroxyl group. ${ }^{12,36}$

Lymphocytes are among the most useful radiosensitive cells for studying the biological effects of radiation. Their advantages over other human cells include the fact that they can be easily obtained in large numbers, do not require cell culture facilities, are diploid and are almost all in the same phase of the cell cycle $\left(G_{0}\right)^{21,22}$ They are highly specialised and potentially reflect the overall state of the organism as they circulate throughout the entire body. ${ }^{35}$ While the findings of the current study indicate a potential new radioprotective agent, further in vivo studies are needed to confirm the safety and efficacy of serinemagnesium sulfate in terms of preventing $\gamma$-radiationinduced DNA damage.

\section{Conclusion}

The findings of this study propose the use of a serinemagnesium sulfate mixture as a new, non-toxic and more potent and efficient radioprotective agent against $\gamma$-radiation cytotoxicity and genotoxicity. However, extensive human as well as animal studies are needed to confirm the safety and efficacy of this agent.

\section{CONFLICT OF INTEREST}

The authors declare no conflicts of interest. 


\section{FUNDING}

This study was funded by the Iran University of Medical Sciences \& Health Services (grant \#27817).

\section{References}

1. International Atomic Energy Agency. Effects of Ionizing Radiation on Blood and Blood Components: A survey. Vienna, Austria: International Atomic Energy Agency, 1997. Pp. 7-17.

2. International Atomic Energy Agency. Cytogenetic Analysis for Radiation Dose Assessment: A manual. Vienna, Austria: International Atomic Energy Agency, 2001. Pp. 4-12.

3. International Atomic Energy Agency. Radiation Biology: A handbook for teachers and students. Vienna, Austria: International Atomic Energy Agency, 2010. Pp. 13-32.

4. El Yamani N, Collins AR, Rundén-Pran E, Fjellsbø LM, Shaposhnikov S, Zielonddiny S, et al. In vitro genotoxicity testing of four reference metal nanomaterials, titanium dioxide, zinc oxide, cerium oxide and silver: Towards reliable hazard assessment. Mutagenesis 2017;32:117-26. doi:10.1093/mutage/ gew060.

5. Collins AR, Azqueta A. DNA repair as a biomarker in human biomonitoring studies: Further applications of the comet assay. Mutat Res 2012; 736:122-9. doi: 10.1016/j.mrfmmm. 2011.03 .005

6. Speit G, Rothfuss A. The comet assay: A sensitive genotoxicity test for the detection of DNA damage and repair. Methods Mol Biol 2012; 920:79-90. doi: 10.1007/978-1-61779-998-3 6 .

7. Nikzad S, Baradaran-Ghahfarokhi M, Nasri P. Dose-response modeling using MTT assay: A short review. Life Sci J 2014; 11:432-7.

8. Nikzad S, Hashemi B. MTT assay instead of the clonogenic assay in measuring the response of cells to ionizing radiation. J Radiobiol 2014; 1:3-8. doi: 10.15171/jrb.2014.02.

9. Kennelly PJ, Rodwell VW. Amino acids and peptides. In: Rodwell VW, Bender DA, Botham KM, Kennelly PJ, Weil PA, Eds. Harper's Illustrated Biochemistry, 30th ed. New York, USA: McGraw-Hill, 2015. Pp. 15-24.

10. Gudkov SV, Popova NR, Bruskov VI. Radioprotective substances: History, trends and prospects. Biophys 2015; 60:659-67. doi: 10.1134/S0006350915040120.

11. Demirel C, Kilçilksiz S, Ay OI, Gürgül S, Ay ME, Erdal N. Effect of $\mathrm{N}$-acetylcysteine on radiation-induced genotoxicity and cytotoxicity in rat bone marrow. J Radiat Res 2009; 50:43-50. doi: 10.1269/jrr.08066

12. Shetab-Boushehri SV, Shetab-Boushehri SF, Abdollahi M. Possible role of $\mathrm{Mg} 2+$ ion in the reaction of organophosphate (dichlorvos) with serine. J Med Hypotheses Ideas 2012; 6:53-7. doi: 10.1016/j.jmhi.2012.05.001

13. Dell RB, Holleran S, Ramakrishnan R. Sample size determination. ILAR J 2002; 43:207-13. doi: 10.1093/ilar.43.4.207.

14. Young DS, Bermes EW. Specimen collection and processing: Sources of biological variation. In: Burtis CA, Ashwood ER, Eds. Tietz Textbook of Clinical Chemistry, 3rd ed. Philadelphia, Pennsylvania, USA: Saunders, 1999. Pp. 42-72.

15. Freshney RI. Culture of Animal Cells: A manual of basic technique and specialized applications, 6th ed. Hoboken, New Jersey, USA: Wiley-Blackwell, 2010. P. 367.

16. Wilson AP. Cytotoxicity and viability assays. In: Masters JR, Ed. Animal Cell Culture: A practical approach, 3rd ed. Oxford, UK: Oxford University Press, 2010. Pp. 175-220.

17. Singh NP, McCoy MT, Tice RR, Schneider EL. A simple technique for quantitation of low levels of DNA damage in individual cells. Exp Cell Res 1988; 175:184-91. doi: 10.1016/ 0014-4827(88)90265-0.
18. Gyori BM, Venkatachalam G, Thiagarajan PS, Hsu D, Clement MV. OpenComet: An automated tool for comet assay image analysis. Redox Biol 2014; 2:457-65. doi: 10.1016/j.redox.2013.12.020.

19. Wilkins RC, Kutzner BC, Truong M, Sanchez-Dardon J, McLean JR. Analysis of radiation-induced apoptosis in human lymphocytes: Flow cytometry using annexin $\mathrm{V}$ and propidium iodide versus the neutral comet assay. Cytometry 2002; 48:14-19. doi: $10.1002 /$ cyto. 10098 .

20. Fairbairn DW, Olive PL, O'Neill KL. The comet assay: A comprehensive review. Mutat Res 1995; 339:37-59. doi: 10.1016/ 0165-1110(94)00013-3

21. Vignon C, Debeissat C, Georget MT, Bouscary D, Gyan E, Rosset $\mathrm{P}$, et al. Flow cytometric quantification of all phases of the cell cycle and apoptosis in a two-color fluorescence plot. PLoS One 2013; 8:e68425. doi: 10.1371/journal.pone.0068425.

22. Yusuf I, Fruman DA. Regulation of quiescence in lymphocytes. Trends Immunol 2003; 24:380-6. doi: 10.1016/S14714906(03)00141-8.

23. Sprince H, Parker CM, Smith GG, Gonzales LJ. Protection against acetaldehyde toxicity in the rat by L-cysteine, thiamin and L-2-methylthiazolidine-4-carboxylic acid. Agents Actions 1974; 4:125-30. doi: 10.1007/BF01966822.

24. Goldenthal EI. A compilation of LD50 values in newborn and adult animals. Toxicol Appl Pharmacol 1971; 18:185-207. doi: 10.1016/0041-008X(71)90328-0.

25. Tada Y, Yano N, Takahashi H, Yuzawa K, Ando H, Kubo Y, et al. A 90-day feeding toxicity study of I-serine in male and female Fischer 344 rats. J Toxicol Pathol 2010; 23:39-47. doi: 10.1293/ tox.23.39.

26. Keller RJ. Principles of toxicology. In: Luttrell WE, Jederberg WW, Still KR, Eds. Toxicology Principles for the Industrial Hygienist. Fairfax, Virginia, USA: American Industrial Hygiene Association, 2008. Pp. 7-13.

27. Prescott L. Oral or intravenous $\mathrm{N}$-acetylcysteine for acetaminophen poisoning? Ann Emerg Med 2005; 45:409-13. doi: 10.10 16/j.annemergmed.2004.09.028

28. Enjalbert F, Rapior S, Nouguier-Soulé J, Guillon S, Amouroux N Cabot C. Treatment of amatoxin poisoning: 20-year retrospective analysis. J Toxicol Clin Toxicol 2002; 40:715-57. doi: $10.1081 /$ CLT-120014646.

29. Shadnia S, Ashrafivand S, Mostafalou S, Abdollahi M. $\mathrm{N}$-acetylcysteine a novel treatment for acute human organophosphate poisoning. Int J Pharmacol 2011; 7:732-5. doi: 10.3923/ijp.2011.732.735.

30. Asevedo E, Mendes AC, Berk M, Brietzke E. Systematic review of N-acetylcysteine in the treatment of addictions. Rev Bras Psiquiatr 2014; 36:168-75. doi: 10.1590/1516-4446-2013-1244.

31. Zheng S, Newton GL, Gonick G, Fahey RC, Ward JF. Radioprotection of DNA by thiols: Relationship between the net charge on a thiol and its ability to protect DNA. Radiat Res 1988; 114:11-27. doi: $10.2307 / 3577140$.

32. Moffat AC, Osselton MD, Widdop B, Eds. Clarke's Analysis of Drugs and Poisons, 4th ed. London, UK: Pharmaceutical Press, 2011. P. 823.

33. Pajoumand A, Shadnia S, Rezaie A, Abdi M, Abdollahi M. Benefits of magnesium sulfate in the management of acute human poisoning by organophosphorus insecticides. Hum Exp Toxicol 2004; 23:565-9. doi: 10.1191/0960327104ht489oa.

34. Prescott LF, Donovan JW, Jarvie DR, Proudfoot AT. The disposition and kinetics of intravenous $\mathrm{N}$-acetylcysteine in patients with paracetamol overdose. Eur J Clin Pharmacol 1989; 37:501-6. doi: 10.1007/BF00558131

35. Silberberg M. Principles of General Chemistry, 2nd ed. New York, USA: McGraw-Hill, 2009. P. 273.

36. Romani AM. Cellular magnesium homeostasis. Arch Biochem Biophys 2011; 512:1-23. doi: 10.1016/j.abb.2011.05.010. 